\title{
Review Paper: Challenges and Limitations in Studying the Shrink-Swell and Crack Dynamics of Vertisol Soils
}

\author{
Takele M. Dinka ${ }^{1}$, Robert J. Lascano ${ }^{2 *}$ \\ ${ }^{1}$ Department of Soil and Crop Sciences, Texas A\&M University, College Station, TX, USA; ${ }^{2}$ USDA-ARS ${ }^{\#}$ Cropping Systems Re- \\ search Laboratory, Wind Erosion and Water Conservation Research Unit, Lubbock, TX, USA. \\ Email: takele2004@yahoo.com, ${ }^{*}$ Robert.Lascano@ars.usda.gov
}

Received February $29^{\text {th }}, 2012$; revised March $26^{\text {th }}, 2012$; accepted April $11^{\text {th }}, 2012$

\begin{abstract}
The need to study the shrink-swell and crack properties of vertic soils has long been recognized given their dynamics in time and space, which modifies the physical properties that impact water and air movement in the soil, flow of water into the subsoil and ground water, and generally alter the hydrology of vertic soils. Measurement of crack properties has been made by numerous researchers with the purpose to understand and quantify the spatial and temporal dynamics of shrinking and swelling and the associated formation of cracks. These crack properties, which are important in modifying hydrology of soils are: width, length, depth and orientation of soil's cracks. To better understand the hydrology of vertic soils and incorporate crack properties into hydrologic simulation models, several techniques have been developed to measure crack properties. However, little attention is given to evaluate both the advantages and the limitations associated with these techniques. Thus, the purpose of this review is to highlight challenges and limitations that have been used or might be used to measure cracking in vertic soils.
\end{abstract}

Keywords: Shrink-Swell; Crack Dynamics; Crack Properties

\section{Introduction}

According to the USDA soil classification, Vertisols are clayey soils ( $>30 \%$ clay) that have deep, wide cracks for some time during the year and have slickensides within $100 \mathrm{~cm}$ of the mineral soil surface. Vertisols cover roughly 308 million ha globally [1] and 18 million ha in the USA [2]. Cover of Vertisols and vertic integrades is estimated to be 320 million ha worldwide [3]. These soils swell when they are wet, shrink when they are dry and form cracks during dry seasons. Wide and deep cracks have a capacity to enhance rapid flow of water and nutrients in the subsoil, modifying the hydrology of the soils $[4,5]$.

Many studies have looked at the dynamics of soil shrinking and swelling and associated crack formation for the purpose of improving hydrology models [6-11]. While the literature is clear on understanding the shrinking and swelling of soil cores and attempts are made to translate some of the knowledge to field observations of

\footnotetext{
${ }^{*}$ Corresponding author.

\#The US Department of Agriculture (USDA) prohibits discrimination in all its programs and activities on the basis of race, color, national origin, age, disability, and where applicable, sex, marital status, familial status, parental status, religion, sexual orientation, genetic information, political beliefs, reprisal, or because all or part of an individual's income is derived from any public assistance program.
}

soil shrinkage, a paucity of observations and knowledge of soil cracking exists. For example, how a soil is expected to shrink in the field can be modeled; however, several assumptions must be made to simulate properties of the cracks, e.g., opening, area density, depth and orientation. The difficulty with modeling actual crack dynamics arises from the inability to realistically measure these crack dimensions in the field and at the appropriate scale. Moreover, the shrink-swell dynamics and potential of a soil also varies considerably with time and scale.

In space, shrink-swell properties of Vertisols vary as a function of soil properties, microclimate, topography, vegetation, cropping patterns, and soil management practices [12-19]. Soil properties that vary in space include clay content and mineralogy, and water holding capacity $[12,13,15,16,20,21]$. Large concentrations of clay, mainly the fine clay fraction, result in large specific surface area that helps store water [19]. As a result, when the soil water content increases, the surface area of the fine clay adsorbs water and the volume increases.

Among all factors, the temporal shrinking and swelling of Vertisols is mainly governed by the amount and distribution of water in the soil, which is a function of clay content, weather patterns, landscape positions and vegetation type. The annual and seasonal variability of 
weather patterns (evapotranspiration) causes a variation in the amount of soil water and in the temporal and spatial distribution of soil water that all affect the shrinkswell dynamics of soils. Soil water may be large at lower positions in the landscape because of sub/surface flow of water, and/or shallow ground water. In some cases, increased abundance of fine clay particles (large porosity) from weathering and deposition at the lower positions in the landscape may also enhance the overall wetness of the soils, e.g., [22,23]. Root patterns and depths vary by vegetation type and influence evapotranspiration that affect the rate of water extraction from the soils and hence soil shrinking. In contrary, roots may change the size and pattern of cracks by holding soils together, thus limiting soil shrinkage [24]. The dependency of shrink-swell and crack dynamics on several spatially and temporally variable factors makes field and laboratory measurement and modeling of soil cracks challenging, i.e., from finding the appropriate measurement technique to the appropriate experimental design.

Experiments with natural soil clods and small soil cores have established a well known functional relation known as the Soil Shrinkage Characteristic Curve (SSCC) $[11,25]$. The four soil shrinking phases in SSCC are: 1) structural; 2) basic; 3) residual; and, 4) zero [25-31]. Each shrinking phase has a different relationship with change in soil water storage, which further challenges the understanding and modeling of the shrink-swell phenomena under different scales (Figure 1). In the structural shrinkage phase, there is no considerable change in bulk volume because water is lost from large macropores [19, 25]. In the basic shrinkage phase, water is lost from the inter-particle pores. The amount of water lost from the soil is equal to the volume of soil shrunken, resulting in a 1:1 relationship between moisture ratio (ratio of volume of void to volume of solid soil) and void ratio (ratio of volume of water to volume of solid soil) $[5,19]$. Basic shrinkage (normal shrinkage) accounts for the majority of soil shrinkage and is reported to occur between soil

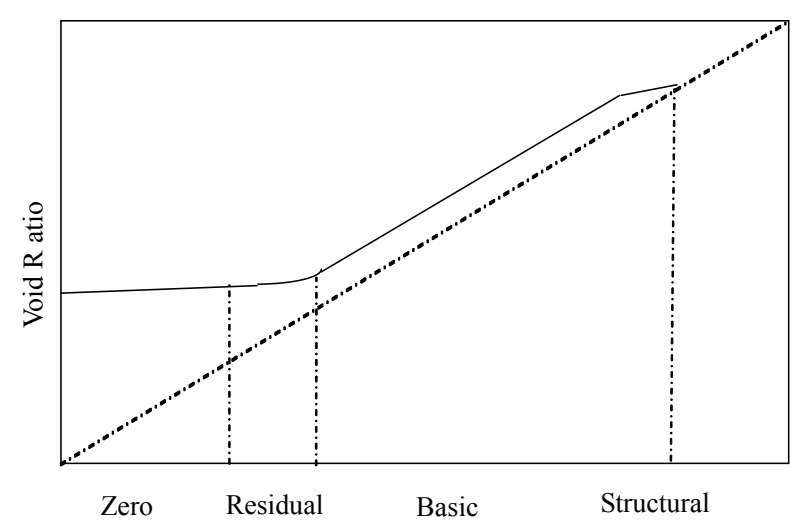

Figure 1. Soil shrinkage characteristic curve and the associated shrinkage phases. water potentials of -33.3 to $\leq-1500 \mathrm{kPa}$. Residual shrinkage occurs when the change in volume of the soil is less than the volume of water lost [28]. In zero shrinkage, the soil volume does not decrease any further with water loss and water loss is equal to the increase of air volume in the soil aggregates [7].

Although the significance of incorporating the crack dynamics of Vertisols into hydrology models is well understood, measurements of crack area density, crack depth, crack volume (capacitance), crack orientations, crack network and time of crack opening and closing are challenging. Current estimates of soil cracking usually assume equi-dimensional shrinkage, in which vertical and horizontal shrinkages are assumed to be equal. Hence, in the field, vertical movement of soil can be measured using rods anchored at different depths in a soil, e.g., [6,32, 33]. Measuring horizontal shrinkage is more difficult because of the irregular geometry and spatial distribution of soil cracks [34]. Combining the equi-dimensional shrinkage model with field measurements of soil subsidence is not very helpful in estimating crack characteristics. Many assumptions are made to link the measurements of soil subsidence and soil water to estimate or calculate crack information. Due to lack of adequate measurement methods for measuring soil cracking on a representative spatial scale, too few studies have been conducted on soil cracking in the field $[5,8,9,35]$.

In the literature, little attention is given to examination of techniques used to measure or estimate soil cracks. Thus, the purpose of this review is to discuss challenges and limitations of techniques used to measure soil cracking. Particularly, the techniques used are evaluated based on their ability to take frequent and/or continuous measurements, the uncertainty of each measurement, and the scale the measurement represents. Since water is usually measured during the crack study, challenges associated with soil water measurement in a field and the experimental design for the measurement of soil crack and soil water in a field is also discussed briefly. Our goal for this review is to stimulate discussion and to encourage those interested in soil cracking studies to continue our interdisciplinary search for better measurement techniques.

\section{Measurement Techniques}

Past studies of soil swelling and shrinking behavior has involved measurement of the ability of the soil to make cracks, i.e., soil shrinkage and soil shrink-swell potential, and actual crack dimensions (length, width, depth and orientation). These measurements have been done in the laboratory and/or in the field (in-situ), each requiring different techniques. The advantages and limitations of field and laboratory measurements techniques are discussed in detail in the following sections. 


\subsection{Field Measurement Techniques}

The most useful insight on soil cracking is likely to be gathered by making crack observations in-situ, under field conditions. The challenge for such measurements is devising a method that can take measurements at an adequate time and/or spatial scale. Several studies have characterized and quantified the shrink-swell properties of soil and associated crack formation among landscapes, land use types and management systems. Reported methods for measuring shrink-swell dynamics in-situ are direct crack width and length measurements made by hand using a ruler $[5,9,10,35]$, measurement of vertical movement of soils $[6,7,32,36]$, surface photography [34] and electrical resistivity measurement $[37,38]$.

Direct crack measurements can provide information on surface crack density and orientation, and help estimate crack volume. This technique helps measure characteristics of cracks but it is time consuming for measurements at significant spatial scales. In direct measurement, the depth, width and length of cracks are measured by hand using rulers and tape measures. For instance, Kishné et al. $[8,9]$ measured the surface width, length, and location of cracks on a $100-\mathrm{m}^{2}$ area $(10 \mathrm{~m} \times 10 \mathrm{~m})$ in Texas using a $1 \mathrm{~m}$ by $1 \mathrm{~m}$ frame with a grid of $0.1-\mathrm{m}$ cell size placed on the soil surface. Though this method resulted in a detailed 10-year data set on crack area density, the method is tedious. For example, it took 3 - $4 \mathrm{~h}$ to take one measurement from the area during a cracking event (personal communication, Wes Miller). Because one measurement takes so long to collect, these measurements only provide snap-shots, prohibiting continuous monitoring of soil shrinkage. Additionally, the method only provides surface information with limited depth information. Width of cracks below the soil surface is difficult to measure with this technique. The accuracy of a direct measurement is also questionable. Rivera [39] graphed handmeasured crack volume data vs. the calculated crack volume based on field-measured soil vertical movement at two different locations. The results of this comparison showed coefficient of simple determination $\left(\mathrm{r}^{2}\right)$ values of 0.12 and 0.10 , but more importantly, the magnitude of the difference was exceptional.

Measurements of vertical shrinkage, made by measuring changes in rod heights anchored at different soil depths, can provide estimates of crack volume, e.g., [6,7]. To do so, a monument, which serves as a non-moving reference, is anchored deep below the surface $(\sim 3 \mathrm{~m})$ or into bedrock. The heights of the rods relative to the monument are measured using surveying equipment, such as a digital level and stadia rod. The changes in heights of the rods are then used to track the temporal vertical movement of soil layers. Anchoring rods at different depths provides information about the shrink-swell activity, incrementally with depth. Because the measurement is re- latively quick (compared to hand measurement), multiple locations can be measured in one day. Therefore, the rodbased vertical shrinkage measurement allows for multiple locations across a landscape to be monitored. In addition, installation of the rods is rather quick with the use of a hydraulic probe. However, taking a measurement requires two people to be present, hence is labor intensive, and comparison of soil shrinkage layer by layer using this technique may not provide an adequate result unless the soil layers move uniformly across a sample area. Moreover, the use of vertical shrinkage data for hydrology models requires estimation of a crack volume using assumptions such as equi-dimensional shrinkage. Instead of rods, though it is not documented yet, magnets along a soil profile may also be used to monitor vertical movement of soils. A magnet sensor would sense the location of the installed magnets in the soil profile and help monitor the temporal variation of the location as influenced by the vertical movement of the soil. The benefit of use of the magnets is that the measurement is faster; soil shrinking at different soil layers can be taken at one position and hence comparison of shrinkage based on soil layer is very easy.

Photography has been used to quantify crack area density directly. Peng et al. [34] measured soil cracks by digital image analysis and were able to identify crack changes as small as $1.0 \mathrm{~mm}^{2}$. The digital image analysis method is advantageous because measurements can be taken repeatedly, continuously, and non-destructively. Though its use in the field does not measure crack depth, image analysis helps determine the crack area density at the surface. The benefit of photography is that a timelapse camera could take short-term temporal variation of cracks and crack opening. Subjectivity on image processing [34] and on selection of a representative site has to be minimized to get a best result. As outdoor cameras become less expensive, photography becomes a feasible method for quickly covering a large area. The major impasse is the presence of vegetation, which either must be sparse or removed so that cracks are visible. For instance, Velde [40] took images of cracks from a cultivated field where cracks were clearly visible. Vegetation enhances water loss, so removing vegetation may affect crack dynamics and our ability to monitor cracking non-invasively over time.

Electrical resistivity tomography in soils is used to look at temporal dynamics of wetness and indirectly understand the crack depth and volume [41], apart from using it to measure cracks under laboratory conditions [37,38]. Amidu and Dunbar [41] used this technique to quantify the effect of gilgai and cracks on soil water content variability of a Texas Vertisols and found different soil water regime with depth that occurred due to preferential flow of water and micro-relief topography. The 
field application of the technique is easy because it is noninvasive. However, interpretation of resistivity requires separation of changes in water content and crack development, which both affect resistivity of the soil; therefore, calibration of the instrument is necessary. Moreover, the technique is not sensitive to crack orientation and the isotropic shrinkage property of soils.

Filling a crack with a known volume of sand might also be applied to estimate a crack volume in a field. However, we have not seen any report about its field application. This technique could be labor and resource intensive and hence cannot be applied to large areas. Furthermore, the application of sand may also modify the soil environment and results obtained would be difficult to interpret.

\subsubsection{Experimental Design}

Experimental design in a field can be challenging for a study of shrink-swell and crack dynamics. For instance, selection of representative soil depth and site(s) to measure cracks and soil shrinkage requires a thorough investigation of the spatial variability of the area. While the study of the dynamics at several depths provides more data, availability of resources limits its field application. Studies also suggest that measurement of soil shrinkage at $0.15 \mathrm{~m}$ soil depth would be enough to get total crack volume of a soil $[5,6]$. However, cracks up to $1.0 \mathrm{~m}$ deep on a grazed pasture in central Texas, and cracks up to $1.40 \mathrm{~m}$ deep were observed in the Gulf Coast Prairie of Texas [42]. The decision of to what depth to measure soil shrinkage needs to be based on, but not limited to, the depth of soils, the degree of soil water content fluctuation in the soil layer and through the soil profile, the amount of inorganic carbon, and depth and pattern of plant roots. Because of a spatial variation in clay, soil water content and inorganic carbon across a catena, soil shrinkage and crack formation can exhibit a similar degree of spatial variability. The variability in degree of changes of water in space affects the size and depth of cracks. Usually, cracks become narrower in the subsoil rather than at the surface because there is less drying in the subsoil. Inorganic carbon reduces soil shrinkage by dilution and/or by cementing aggregates together $[43,44]$ and hence its variability with depth (generally increases with depth) and across a landscape affects the choice of measurement depth and location. Roots depth and pattern also govern soil water loss through transpiration and hence affect soil shrinking, therefore, must also be considered in experimental design.

The presence of gilgai (surface micro-topography) and associated subsurface features make the experimental design and the measurement of soil vertical shrinkage more complex [42]. Shape, size, depth and length of gilgai modify the shrink-swell dynamics of soils across a space and complicate placement of measurements [9] and two types of gilgai in the Central Texas were observed: circular and linear. Absence of clear understanding on the relationship between microhighs/microlows and cracks represent an additional challenge. For instance, there are studies that indicate that microhighs have a greater crack density than microlows $[9,41]$, while others reported greater crack density on microlows [45]. Presence of gilgai in a field may affect the soil layer continuity, which also limits comparison of soil subsidence layer-by-layer across a field.

Kishné et al. [9] and Knight [46] reported a relatively greater amount of soil water content in the circular microlow than in the microhigh in Vertisols of Central Texas [9] and Victoria, Australia [46], which makes soils in the microlows wetter than microhighs, and hence less cracks in the microlow. Nonetheless, because of the wetness, more vegetation is common in microlows than in the microhighs. The presence of vegetation could increase cracking by enhancing loss of water through evapotranspiration [46] and at the same time slowdown soil cracking by keeping soils together with their roots [24]. Therefore, the crack variability associated with microhighs and microlows must be considered at that scale.

In addition to the measurement techniques used, the type of study (whether it is in a laboratory or field) affects the result and interpretation of the shrinkage properties of soils. Bronswijk [7] developed equations that relate vertical soil subsidence and-crack volume to change in soil water storage based on the assumption of isotropic shrinkage and used in the SWAT hydrology model [6]. However, there is evidence suggesting that soils do not always shrink equally from all sides. Peng et al. [34] found that vertical and horizontal soil shrinkages are anisotropic and Cabidoche and Ozier-Lafontaine [47] found a vertical soil movement slightly greater than horizontal movement, claiming that soils slide along slickensides during shrinking that limits the opening of the cracks. However, in small cores where slickensides are less observed, shrinkage of small soil cores is isotropic $[30,33]$. This lack of consensus on the shrinkage property of soils could be due to differences in the measurement scale in addition to the measuring techniques.

\subsubsection{Measuring Soil Water Content in Vertisols}

Since soil water is the main governing factor for shrinking and swelling of soils and formation of cracking, thus measuring soil water content is equally important as measuring cracking. Usually, the neutron attenuation method is used to measure soil water content in cracking soils $[32,48]$ because it minimizes soil disturbances, and is non-destructive [49], and quicker than gravimetric sampling. Use of other soil water measuring methods, such as time domain reflectometry and other electromag- 
netic sensors is of limited use in Vertisols because cracks separate the soil from the sensors and or a limited sphere of measurement by the sensors and hence our discussion focuses on the neutron attenuation method. The large sphere of influence of a neutron meter reduces the effect of cracking on the soil water measurement and does not require the sensor to be in direct contact with the soil. A neutron meter can sense a soil volume that ranges from $900 \mathrm{~cm}^{3}$ to $4.2 \mathrm{~m}^{3}$ (a diameter of $97 \mathrm{~mm}$ to $1.6 \mathrm{~m}$ ) of soils at very wet and dry conditions, respectively [50]. A relationship between soil water content and soil subsidence measurements, therefore, can be developed with confidence, provided a calibration between neutron counts vs. volumetric soil water content is established. A good calibration is achieved when all the variables, which may vary in time and space and affect volumetric water content of soils, are addressed and considered during the calibration process.

Establishing a calibration of a neutron meter in a Vertisol is critical and it can be different from calibrations in other soils, because Vertisols change volume upon drying. Literature on calibration of neutron meters is abundant [49,51-56]. Usually the calibration of the neutron meter is done in a field but if it is made on a packed barrel, a subsequent adjustment of the calibration based on soil volume change is suggested [48], though the technique is tedious. Because of its simplicity, a field calibration for Vertisols at dry and wet soil conditions is preferred. A field calibration in dry conditions automatically accounts for volumetric changes. More than one calibration site may be needed depending on the objective of the research. If it is to do a long-term measurement over a wide area, the calibration model needs to address the spatial variability of soil properties such as clay content and inorganic carbon [57] that could affect the reading of soil water content.

While collecting soil water measurement over time with a neutron meter, the distance between the soil surface and the top of the neutron access tube varies because the soil height changes. During soil drying or wetting, measurements taken at a constant distance from the top of the access tube will be at different depths in the soil, depending on the magnitude of the soil vertical movement [48]. Based on our observation, the distance can vary up to $50 \mathrm{~mm}$ from its origin. Placing a neutron meter on a stand with a constant height above soil surface avoids this problem $[48,57]$. Presence of cracks near the access tube can affect soil water measurement. If a rain falls when cracks are open, runoff may accumulate between the outer side of the neutron access tube and the soil wall, which can result in overestimation of soil water content in the soil profile. Moreover, since we observed an access tube with free water inside, the access tubes have to be checked for wetness before taking a measurement or have to be sealed at the bottom during installation. Assessing free water inside and around the access tube before measurement is, therefore, important to reduce a measurement error.

\subsection{Laboratory Measurement Techniques}

Soil shrink-swell potential along with water content measurements is a common way to estimate soil cracks in hydrology models. The relationship between soil shrinkswell potential and soil physical and chemical properties has been studied [19,30,58-62]. Major soil properties correlated with soil shrink-swell potential are fine clay and total clay content, water holding capacity, dry and wet bulk density, inorganic and organic carbon, specific surface area and exchangeable cations. Researchers have reported similar and contradicting results about shrinkswell potential and soil properties as discussed below.

Clays in Vertisols have a large surface area and minerals (mainly smectitic) that make them have large shrinkswell potential and most studies show a positive and strong correlation between soil shrink-swell potential and total clay content $[16,19,58,61,62]$. In contrast, Yule and Ritchie [30] and Gray and Allbrook [59] found no relationship between clay content and soil shrinking potential in their studies. However, Gray and Allbrook [59] had allophone in the clay-size fraction and once allophone was removed, a better relationship between clay content and shrink-swell potential were found. The soils studied by Yule and Ritchie [30] ranged in clay content from 45 to $70 \%$. At this range, likely other soil properties dominated the variability in shrink-swell potential. Regardless, McCormack and Wilding [60] concluded that clay content is a reliable source to calculate and predict shrinkswell potential.

The Coefficient of Linear Extensibility (COLE) of soil is used to describe the shrink-swell potential of natural soil clods and gives the relative potential of soils to shrink and swell from a water potential of $-33.3 \mathrm{kPa}$, i.e., field capacity, to oven dry $[7,21,61,63]$. The COLE is usually calculated by using the difference in volume of a soil clod measured at $-33.3 \mathrm{kPa}\left(V_{m}\right)$ and measured after oven dried $\left(V_{d}\right)$, as follows:

$$
\text { COLE }=\frac{\left(V_{m}^{1 / 3}-V_{d}^{1 / 3}\right)}{V_{d}^{1 / 3}}
$$

The soil water content, especially oven dry, does not accurately represent field wetness. Therefore, measuring the shrinkage limit of soil clods at an oven dry condition may overestimate the soil shrinkage potential expected to occur under field conditions. In the calculation of COLE, swelling of soils beyond $-33.3 \mathrm{kPa}$ is also ignored. Because Vertisols are high in clay content ( $>30 \%)$, the field 
capacity of the soil may go beyond the commonly assumed soil water potential of $-33.3 \mathrm{kPa}$; therefore, we might expect the soil to swell at soil water wetter than $-33.3 \mathrm{kPa}$. To account for this discrepancy in clayey materials a value of $-10 \mathrm{kPa}$, instead of $-33.3 \mathrm{kPa}$, has been used to represent the soil water potential at field capacity [64].

In most studies, the volume of soil clods is measured based on Archimedes's law, i.e., the clod is immersed in water, and the volume of water displaced by the clod is the same as the volume of the clod. To avoid penetration of water into clods during immersion, clods are usually coated with Saran or a paraffin wax. The advantages of Saran coating clods are that soil samples are intact (natural fabric) and the measurement error is low [25]. It has been reported that the classical Saran method limits water penetration during immersion, requires a correction for the volume of Saran coatings, may limit swelling, and may not properly shrink with the clod $[65,66]$. Moreover, Saran-coated clods may not be reused for other analysis, like chemical analysis or volume measurement at multiple water contents. As a result, distinct samples are required for each analysis [25,65], which makes the method resource demanding. The COLE measurements can also vary depending on the water content a soil clod is coated and studies show that wetting of clods before coating results in greater COLE values [58,66]. As an alternative to the Saran method, use of a three-dimensional (3D) image scanner that measures volume of soil clods, allows volume measurement of a single clod at multiple soil water potentials. The disadvantage of the $3 \mathrm{D}$ scanner is that it is time-consuming ( $>1 \mathrm{~h}$ per clod) and image processing is prone to subjectivity.

In addition to the Saran coating technique, pedo-transfer functions have been used to estimate COLE. Interpretations of the relationship between soil properties and shrink-swell potential of a soil requires a clear mechanistic explanation of how soil properties determine shrinkswell potential. The relationships between COLE and soil properties have been successfully implemented; but results are not consistent. For instance, McCormack and Wilding [60] calculated a multiple regression to relate COLE to soil properties including fine, coarse and total clay, and soil water content at $-1500 \mathrm{kPa}$. Surprisingly, none of the variables was significant when total clay content was included. Anderson et al. [58] and Smith et al. [16] also found a positive correlation between COLE and exchangeable sodium percentage, while Gray and Allbrook [59] found no significant relationship because the soils had low concentrations of exchangeable cations.

Organic matter improves soil structure and increases soil porosity; therefore, if a soil holds more water, it may shrink more upon drying. Conversely, if the water is held in larger pores, the effect of organic matter on shrink- swell could be to reduce shrink-swell potential because the water loss is structural (Figure 1). For this reason, the relationship between organic matter and soil shrinkage is not simple [59] and contrary results have been found and reported. For instance, a positive correlation was reported between organic carbon and shrinkage in both topsoil and subsoil by Reeve et al. [61], while Smith et al. [16] reported no significant relationship. Moreover, Davidson and Page [12] reported that removal of organic matter increases swelling capacity of soils, claiming that adsorption of organic matter on soil clays modifies the swelling property of the clay.

\section{Summary}

A mechanistic understanding of soil crack formation and geometry for in-situ conditions is not well known. Clearly, exploration of soil cracking is very limited by the difficulty in observing the shrink-swell phenomena, particularly observations that are minimally invasive, allowing monitoring of cracking with time. Current techniques of measuring soil cracking and the shrink-swell dynamics of Vertisols are far from providing complete information for understanding their impact on large and small-scale hydrological processes [67]. Information needed includes crack area density, depth, orientation and network, opening and closing time, and pattern of formation. No single technique of those reviewed can provide this information continuously, nondestructively and with a reasonable certainty in the field.

While we can currently measure soil subsidence in the field, the relationship between soil subsidence and cracking is poorly developed. Understanding and quantifying the in-situ relationship between change in soil water storage and the mechanisms of cracking, which are vertical cracking, surface and subsurface horizontal cracking and diagonal cracking, is currently a challenge to improve our understanding of how water moves through these cracks. Improving the accuracy and efficiency of promising technologies such as surface photography, electrical resistivity measurement, and use of magnets provide opportunities to collect better information on soil cracking. Particularly when used together or with subsidence information measurements. Laboratory studies are used to measure and model soil shrink-swell potential so that the information can be transferred to hydrology models and applied on landscape and watershed scales. The COLE helps estimate maximum soil shrinkage in a field, and can be converted to crack volume with certain assumptions. However, COLE does not account for temporal variability of soil water change that mainly governs crack formation. Therefore, to estimate the apparent occurrence and volume of cracks, use of COLE should be supported with the temporal change of soil water storage. A combined use of field and laboratory techniques, as- 
sisted by models, may help get all the necessary information. Acquiring crack information will fill the gap in hydrology models that are applied on shrink-swell soils. Developing advanced techniques (both software and hardware) that address the spatial and temporal dynamics of soil shrinkage and crack formation is needed.

\section{Acknowledgements}

This work was partially supported by the Texas AgriLife Research and a Cooperative Agreement with the USDA NRCS Texas Soil Survey and a Grant No. EAR 0911317 from the National Science Foundation.

\section{REFERENCES}

[1] C. E. Coulombe, L. P. Wilding and J. B. Dixon, "Overview of Vertisols: Characteristics and Impacts on Society," Advanced Agronomy, Vol. 57, No. C, 1996, pp. 289375. doi:10.1016/S0065-2113(08)60927-X

[2] Soil Survey Staff, "Soil Survey Laboratory Methods and Procedures for Collecting Soil Samples. Soil Survey Investigations Report No. 42," United States Government Printing Office, Washington DC, 1996.

[3] W. A. Blokhuis, "Vertisols," In: R. Lal, Ed., Encyclopedia of Soil Science, Second Edition, Taylor and Francis, Boca Raton, 2006, pp. 1830-1840.

[4] J. G. Arnold, P. M. Allen, R. Muttiah and G. Bernhardt, "Automated Base Flow Separation and Recession Analysis Techniques," Ground Water, Vol. 33, No. 6, 1995, pp. 1010-1018. doi:10.1111/j.1745-6584.1995.tb00046.x

[5] K. K. Bandyopadhyay, M. Mohanty, D. K. Painuli, A. K. Misra, K. M. Hati, K. G. Mandal, P. K. Ghosh, R. S. Chaudhary and C. L. Acharya, "Influence of Tillage Practices and Nutrient Management on Crack Parameters in a Vertisol of Central India," Soil Tillage Research, Vol. 71, No. 2, 2003, pp. 133-142. doi:10.1016/S0167-1987(03)00043-6

[6] J. G. Arnold, K. N. Potter, K. W. King and P. M. Allen, "Estimation of Soil Cracking and the Effect on Surface Runoff in a Texas Blackland Prairie Watershed," Hydrological Processes, Vol. 19, No. 3, 2005, pp. 589-603. doi:10.1002/hyp.5609

[7] J. J. B. Bronswijk, "Relation between Vertical Soil Movements and Water-Content Changes in Cracking Clays," Soil Science Society of American Journal, Vol. 55, No. 5, 1991, pp. 1220-1226. doi:10.2136/sssaj1991.03615995005500050004x

[8] A. Sz. Kishné, C. L. S. Morgan, Y. Ge and W. L. Miller, "Antecedent Soil Moisture Affecting Surface Cracking of a Vertisol in Field Conditions," Geoderma, Vol. 157, No. 3-4, 2010, pp. 109-117. doi:10.1016/j.geoderma.2010.03.020

[9] A. Sz. Kishné, C. L. S. Morgan and W. L. Miller, "Vertisol Crack Extent Associated with Gilgai and Soil Moisture in the Texas Gulf Coast Prairie," Soil Science Society of American Journal, Vol. 73, No. 4, 2009, pp. 12211230. doi: $10.2136 /$ sssaj2008.0081
[10] A. R. Mitchell, "Soil Surface Shrinkage to Estimate Profile Soil Water," Irrigation Science, Vol. 12, No. 1, 1991, pp. 1-6. doi:10.1007/BF00190702

[11] P. A. Olsen, and L. E. Haugen, "A New Model of the Shrinkage Characteristic Applied to Some Norwegian soils," Geoderma, Vol. 83, No. 1-2, 1998, pp. 67-81. doi:10.1016/S0016-7061(97)00145-6

[12] S. E. Davidson and J. B. Page, "Factors Influencing Swelling and Shrinking in Soils," Soil Science Society of American Journal, Vol. 20, No. 3, 1956, pp. 320-324. doi:10.2136/sssaj1956.03615995002000030007x

[13] R. Dudal and H. Eswaran, "Distribution, Properties, and Classification of Vertisols," In: L. P. Wilding and R. Puentes, Eds., Publication Soil Management Support Services, US Department of Agriculture, Natural Resources Conservation Service, Washington DC, 1988, pp. 1-22.

[14] A. Komornik, "Proceedings of the Second International Research and Engineering Conference on Expansive Clay Soils," Soil Science Society of American Journal, Vol. 70, 1969, pp. 1983-1990.

[15] H. S. Lin, K. J. Mclnnes, L. P. Wilding and C. T. Hallmark, "Macroporosity and Initial Moisture Effects on Infiltration Rates in Vertisols and Vertic Intergrades," Soil Science, Vol. 163, No. 1, 1998, pp. 2-8.

doi:10.1097/00010694-199801000-00002

[16] C. W. Smith, A. Hadas, J. Dan and H. Koyumdjisky, "Shrinkage and Atterberg Limits in Relation to Other Properties of Principal Soil Types in Israel," Geoderma, Vol. 35, No. 1, 1985, pp. 47-65. doi:10.1016/0016-7061(85)90055-2

[17] P. J. Thomas, J. C. Baker, L. W. Zelazny and D. R. Hatch, "Relationship of Map Unit Variability to Shrink-Swell Indicators," Soil Science Society of American Journal, Vol. 64, No. 1, 2000, pp. 262-268. doi:10.2136/sssaj2000.641262x

[18] R. Vaught, K. R. Brye and D. M. Miller, "Relationships among Coefficient of Linear Extensibility and Clay Fractions in Expansive, Stoney Soils," Soil Science Society of American Journal, Vol. 70, No. 6, 2006, pp. 1983-1990. doi:10.2136/sssaj2006.0054

[19] L. P. Wilding and D. Tessier, "Genesis of Vertisols: Shrink-Swell Phenomena," In: L. P. Wilding and R. Puentes, Eds., Vertisols: Their Distribution, Properties, Classification, and Management, Texas A\&M University Printing Center, College Station, 1998, pp. 55-79.

[20] S. Azam, S. Abduljauwad, N. Al-Shayea and O. S. B. Al-Amoudi, "Effects of Calcium Sulfate on Swelling Potential of Expansive Clay," Soil Science Society of American Journal, Vol. 70, No. 6, 2000, pp. 1983-1990.

[21] P. J. Thomas, J. C. Baker and L.W. Zelazny, "An Expansive Soil Index for Predicting Shrink-Swell Potential," Soil Science Society of American Journal, Vol. 64, No. 1, 2000, pp. 268-274. doi:10.2136/sssaj2000.641268x

[22] H. Li, R. J. Lascano, J. Booker, L. T. Wilson and K. F. Bronson, "Nitrogen and Cotton Lint Yield Variability in a Heterogeneous Soil at a Landscape Scale," Soil Tillage Research, Vol. 58, No. 3-4, 2001, pp. 245-258. doi:10.1016/S0167-1987(00)00172-0 
[23] H. Li, R. J. Lascano, J. Booker, L. T. Wilson, K. F. Bronson and E. Segarra, "State-Space Description of Field Heterogeneity: Water and Nitrogen Use in Cotton," Soil Science Society of American Journal, Vol. 66, No. 2, 2002, pp. 585-595. doi:10.2136/sssaj2002.0585

[24] A. R. Mitchell and M. T. van Genuchten, "Shrinkage of Bare and Cultivated Soil," Soil Science Society of American Journal, Vol. 56, No. 4, 1992, pp. 1036-1042. doi:10.2136/sssaj1992.03615995005600040006x

[25] W. M. Cornelis, J. Corluy, H. Medina, J. Díaz, R. Hartmann, M. Van Meirvenne and M. E. Ruiz, "Measuring and Modelling the Soil Shrinkage Characteristic Curve," Geoderma, Vol. 137, No. 1-2, 2006, pp. 179-191. doi:10.1016/j.geoderma.2006.08.022

[26] W. B. Haines, "The Volume-Changes Associated with Variations of Water Content in Soil," Journal of Agricultural Science, Vol. 13, No. 3, 1923, pp. 296-310. doi:10.1017/S0021859600003580

[27] B. A. Keen, "The Physical Properties of the Soil," Quarterly Journal of the Meteorological Society, Vol. 58, No. 247, 1931, pp. 490-491.

[28] G. Stirk, "Some Aspects of Soil Shrinkage and the Effect of Cracking upon Water Entry into the Soil," Australian Journal of Agricultural Research, Vol. 5, No. 2, 1954, pp. 279-296. doi:10.1071/AR9540279

[29] A. U. R. Tariq and D. S. Durnford, "Analytical Volume Change Model for Swelling Clay Soils," Soil Science Society of American Journal, Vol. 57, No. 5, 1993, pp. 1183-1187. doi:10.2136/sssaj1993.03615995005700050003x

[30] D. F. Yule and J. T. Ritchie, "Soil Shrinkage Relationships of Texas Vertisols: I. Small Cores," Soil Science Society of American Journal, Vol. 44, No. 6, 1980, pp. 1285-1291. doi:10.2136/sssaj1980.03615995004400060031x

[31] D. F. Yule and J. T. Ritchie, "Soil Shrinkage Relationships of Texas Vertisols: II. Large Cores," Soil Science Society of American Journal, Vol. 44, No. 6, 1980, pp. 1291-1295. doi:10.2136/sssaj1980.03615995004400060032x

[32] J. U. Baer and S. H. Anderson, "Landscape Effects on Desiccation Cracking in an Aqualf," Soil Science Society of American Journal, Vol. 61, No. 5, 1997, pp. 14971502. doi:10.2136/sssaj1997.03615995006100050029x

[33] J. J. B. Bronswijk, "Shrinkage Geometry of a Heavy Clay Soil at Various Stresses," Soil Science Society of American Journal, Vol. 54, No. 5, 1990, pp. 1500-1502. doi:10.2136/sssaj1990.03615995005400050048x

[34] X. Peng, R. Horn, S. Peth and A. Smucker, "Quantification of Soil Shrinkage in 2D by Digital Image Processing of Soil Surface," Soil Tillage Research, Vol. 91, No. 1-2, 2006, pp. 173-180. doi:10.1016/j.still.2005.12.012

[35] I. Daniells, "Degradation and Restoration of Soil Structure in a Cracking Grey Clay used for Cotton Production," Australian Journal of Soil Research, Vol. 27, No. 2, 1989, pp. 455-469. doi:10.1071/SR9890455

[36] G. D. Aitchenson and J. W. Holmes, "Aspects of Swelling in the Soil Profile," Australian Journal Applied Sci- ence, Vol. 4, 1953, pp. 244-259.

[37] A. Samouëlian, I. Cousin, G. Richard, A. Tabbagh and A. Bruand, "Electrical Resistivity Imaging for Detecting Soil Cracking at the Centimetric Scale," Soil Science Society of American Journal, Vol. 67, No. 5, 2003, pp. 13191326. doi:10.2136/sssaj2003.1319

[38] A. Samouëlian, G. Richard, I. Cousin, R. Guerin, A. Bruand and A. Tabbagh, "Three-Dimensional Crack Monitoring by Electrical Resistivity Tomography," European Journal of Soil Science, Vol. 55, No. 4, 2004, pp. 751-762. doi:10.1111/j.1365-2389.2004.00632.x

[39] L. Rivera, "Comparing Methods of Estimating Crack Volume in Shrink-Swell Soils," A Senior Scholars Thesis, Texas A\&M University, College Station, 2008.

[40] B. Velde, "Structure of Surface Cracks in Soil and Muds," Geoderma, Vol. 93, No. 1-2, 1999, pp. 101-124. doi:10.1016/S0016-7061(99)00047-6

[41] S. A. Amidu and J. A. Dunbar, "Geoelectric Studies of Seasonal Wetting and Drying of a Texas Vertisol," Vadose Zone Journal, Vol. 6, No. 3, 2007, pp. 511-523. doi:10.2136/vzj2007.0005

[42] W. L. Miller, A. Sz. Kishné and C. L. S. Morgan, "Vertisol Morphology, Classification, and Seasonal Cracking Patterns in the Texas Gulf Coast Prairie," Soil Survey Horizons, Vol. 51, 2010, pp. 10-16.

[43] T. L. Deshpande, D. J. Greenland and J. P. Quirk, "Role of Iron Oxide in the Bonding of Soil Particles," Nature, Vol. 201, No. 4914, 1964, pp. 107-108. doi: $10.1038 / 201107 \mathrm{~b} 0$

[44] D. L. Rimmer and D. J. Greenland, "Effects of Calcium Carbonate on the Swelling Behaviour of a Soil Clay," European Journal of Soil Science, Vol. 27, No. 2, 1976, pp. 129-139. doi:10.1111/j.1365-2389.1976.tb01983.x

[45] C. H. Thompson and G. G. Beckmann, "Gilgai in Australian Black Earths and Some of Its Effects on Plants," Tropical Agriculture, Vol. 59, No. 2, 1982, pp. 149-156.

[46] M. J. Knight, "Structural Analysis and Mechanical Origins of Gilgai at Boorook, Victoria, Australia," Geoderma, Vol. 23, No. 4, 1980, pp. 245-283. doi:10.1016/0016-7061(80)90067-1

[47] Y. M. Cabidoche and H. Ozier-Lafontaine, "THERESA: I. Matric Water Content Measurements through Thickness Variations in Vertisols," Agricultural Water Management, Vol. 28, No. 2, 1995, pp. 133-147. doi:10.1016/0378-3774(95)01164-E

[48] J. M. Kirby, A. L. Bernardi, A. J. Ringrose-Voase, R. Young and H. Rose, "Field Swelling, Shrinking, and Water Content Change in a Heavy Clay Soil," Australian Journal Soil Research, Vol. 41, No. 5, 2003, pp. 963-978. doi:10.1071/SR02055

[49] M. Corbeels, R. Hartmann, G. Hofman and O. Van Cleemput, "Field Calibration of a Neutron Moisture Meter in Vertisols," Soil Science Society of American Journal, Vol. 63, No. 1, 1999, pp. 11-18. doi:10.2136/sssaj1999.03615995006300010003x

[50] S. R. Evett, R. C. Schwartz, J. A. Tolk and T. A. Howell, "Soil Profile Water Content Determination: Spatiotemporal Variability of Electromagnetic and Neutron Probe 
Sensors in Access Tubes," Vadose Zone Journal, Vol. 8, No. 4, 2009, pp. 926-941. doi:10.2136/vzj2008.0146

[51] S. R. Evett and J. L. Steiner, "Precision of Neutron Scattering and Capacitance Type Soil Water Content Gauges from Field Calibration," Soil Science Society of American Journal, Vol. 59, No. 4, 1995, pp. 961-968. doi:10.2136/sssaj1995.03615995005900040001x

[52] S. R. Evett, J. A. Tolk and T. A. Howell, "Soil Profile Water Content Determination: Sensor Accuracy, Axial Response, Calibration, Temperature Dependence, and Precision," Vadose Zone Journal, Vol. 5, No. 3, 2006, pp. 894-907. doi:10.2136/vzj2005.0149

[53] E. Greacen and C. Hignett, "Sources of Bias in the Field Calibration of a Neutron Meter," Australian Journal of Soil Research, Vol. 17, No. 3, 1979, pp. 405-415. doi:10.1071/SR9790405

[54] E. Greacen and G. Schrale, "The Effect of Bulk Density on Neutron Meter Calibration," Australian Journal of Soil Research, Vol. 14, No. 2, 1976, pp. 159-169. doi:10.1071/SR9760159

[55] A. S. Hodgson and K. Y. Chan, "Field Calibration of a Neutron Moisture Meter in a Cracking Grey Clay," Irrigation Science, Vol. 8, No. 4, 1987, pp. 233-244. doi:10.1007/BF00257508

[56] N. T. Mazahrih, N. Katbeh-Bader, S. R. Evett, J. E. Ayars and T. J. Trout, "Field Calibration Accuracy and Utility of Four Down-Hole Water Content Sensors," Vadose Zone Journal, Vol. 7, No. 3, 2008, pp. 992-1000. doi:10.2136/vzj2008.0001

[57] S. R. Evett, "Neutron Moisture Meters," In: S. R. Evett, L. K. Heng, P. Moutonnet and M. L. Nguyen, Eds., Field Estimation of Soil Water Content: A Practical Guide to Methods, Instrumentation and Sensor Technology, IAEATCS-30. International Atomic Energy Agency, Vienna, 2008, pp. 39-54.

[58] J. U. Anderson, K. E. Fadul and G. A. O'Connor, "Factors Affecting the Coefficient of Linear Extensibility in Vertisols," Soil Science Society of American Journal, Vol. 37, No. 2, 1973, pp. 296-299. doi:10.2136/sssaj1973.03615995003700020036x

[59] C. W. Gray and R. Allbrook, "Relationships between
Shrinkage Indices and Soil Properties in Some New Zealand soils," Geoderma, Vol. 108, No. 3-4, 2002, pp. 287299. doi:10.1016/S0016-7061(02)00136-2

[60] D. E. McCormack and L. P. Wilding, "Soil Properties Influencing Swelling in Canfield and Geeburg Soils," Soil Science Society of American Journal, Vol. 39, No. 3, 1975, pp. 496-502. doi:10.2136/sssaj1975.03615995003900030034x

[61] M. J. Reeve, D. G. M. Hall and P. Bullock, "The Effect of Soil Composition and Environmental Factors on the Shrinkage of Some Clayey British Soils," European Journal of Soil Science, Vol. 31, No. 3, 1980, pp. 429-442. doi:10.1111/j.1365-2389.1980.tb02092.x

[62] G. J. Ross, "Relationships of Specific Surface Area and Clay Content to Shrink-Swell Potential of Soils Having Different Clay Mineralogical Compositions," Canadian Journal of Soil Science, Vol. 58, No. 2, 1978, pp. 159-166. doi: $10.4141 /$ cjss $78-020$

[63] R. B. Grossman, B. R. Brasher, D. P. Franzmeier and J. L. Walker, "Linear Extensibility as Calculated from NaturalClod Bulk Density Measurements," Soil Science Society of American Journal, Vol. 32, No. 4, 1968, pp. 570-573. doi:10.2136/sssaj1968.03615995003200040041x

[64] I. Messing and N. J. Jarvis, "Seasonal Variation in Field-Saturated Hydraulic Conductivity in Two Swelling Clay Soils in Sweden," European Journal of Soil Science, Vol. 41, No. 2, 1990, pp. 229-237. doi:10.1111/j.1365-2389.1990.tb00059.x

[65] T. Sander and H. H. Gerke, "Noncontact Shrinkage Curve Determination for Soil Clods and Aggregates by ThreeDimensional Optical Scanning," Soil Science Society of American Journal, Vol. 71, No. 5, 2007, pp. 1448-1454. doi: $10.2136 /$ sssaj2006.0372

[66] J. Tunny, "The Influence of Saran Resin Coatings on Swelling of Natural Soil Clods," Soil Science, Vol. 109, No. 4, 1970, pp. 254-256. doi:10.1097/00010694-197004000-00010

[67] P. J. Thomas, "Quantifying Properties and Variability of Expansive Soils in Selected Map Units," Ph.D. Dissertation, Virginia Polytechnic Institute and State University, Blacksburg, 1998. 